\title{
Development opportunities in the mixed-use resort market
}

Received: 1 August 2005

\section{Richard Barnett}

runs his own independent consultancy practice, International Leisure Management, providing development consultancy advice on projects in the hotel, leisure and hospitality field. Most of his work is in the concept planning, market analysis and preconstruction development of mixed-use resorts in Europe. He has worked in over 30 countries across the world and is able to bring a detailed operator/consultant view to new project opportunities.

\section{Abstract}

The mixed-use resort development has been with us for many years, in Europe since charter air travel opened up the tour operator holiday market in the 1960s, and before then in the USA, when people found it very attractive to 'live' in a resort environment.

For the customer/end user the mixed-use resort provides many things; a variety of accommodation styles, sporting and leisure activities, security, a 'lifestyle living experience', for the developer it provides an opportunity to attract different markets, all with different, yet linked, buying motives. This easy blend of comfortable supply and demand characteristics has led many developers to the path of mixed-use resort development. With typical mixed-use resorts costing well in excess of $€_{100}$ million to build out, not too many individuals or companies manage to complete more than one or two projects. This paper seeks to identify the opportunities that exist around the world to create a mixed-use resort environment, and to highlight some of the difficulties a developer might face.

\section{Keywords:}

mixed-use resorts, leisure development, lifestyle living, holiday resort real estate

Richard Barnett International Leisure Management 21 Prince Consort Drive, Chislehurst, Kent QR7 5 SB

Tel: +44 (o)208 2950706

E-mail: rb@ilm-uk.com

\section{MIXED-USE RESORTS}

Mixed-use resort development is very much alive and well, with projects and development opportunities available throughout the world. The synergies of such developments are very attractive to developers - through spreading risk, attracting more than one target market and making the end product more attractive to its users. The objective is to provide a physical environment offering a holiday experience with numerous accommodation types, a variety of sporting and leisure activities and support services within an enclosed or clearly defined area - an integrated resort environment. 
Most developments of this nature will comprise some or all of the following:

- hotel

- real estate (freehold, sale/leaseback, timeshare/fractional, rental)

- retail

- some commercial

- sports/golf/marina

— children's activities.

The integrated resort environment
Each component will be designed to complement the others, thus providing the integrated resort environment: a total experience that means the user does not have to leave the confines of the resort to enjoy a holiday or lifestyle living.

The buying motives of the end user, for a one-time visit or to purchase a home or business, are the same and are inextricably linked (Figure 1).

These buyers can be separated into two distinct types: mature markets, which comprise the UK, northern European markets, the USA and Japan, and new user markets. These are rapidly opening up, with Russia and its new republics, China and Eastern European countries leading the way. The needs and expectations of these source markets are very similar, with sun, sea, sand and sport leading. They are value driven, but not necessarily price conscious. They are buying:

- secure environment

- privacy

- exclusivity

— total service provision

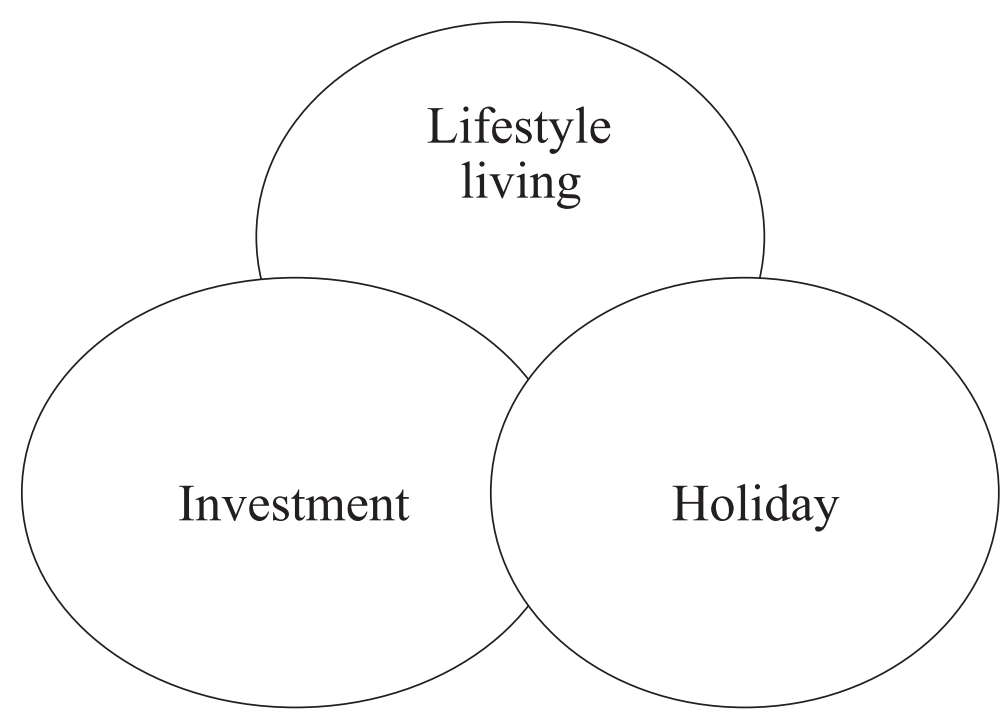

Figure 1: Buying motives for end users 
— investment opportunity

- holiday environment with activities.

This is invariably provided within a destination environment that is driven by:

- sea: destination driven

- golf: sport driven

- marina: activity driven

- spa: relaxation, health, fitness, pampering.

Few resort developments will risk creating an integrated resort destination without the provision of a golf course, but is this really so essential in mature markets where there is a wide choice of such facilities? Why cannot one develop resorts with a focus on something different?

- Educational: activity, interest — academic, task, craft, skills.

- Extreme sports: thrills, adventure.

- Primary living experience: alternative lifestyle (a complete change and not just for holidays).

- Retirement living: staged accommodation offering graduated care progressing to nursing home/hospital.

- Theme-park living: themed lifestyle.

\section{INVESTMENT OPPORTUNITIES}

What attracts a developer into this market? Almost exclusively it is the real estate component - after all, this is where the money is. It is not unusual for the hotel component of a mixed-use resort to attract an IRR of around 18 per cent; with luck retail and commercial can beat this by 5 per cent; the golf, sports and leisure activities might struggle to reach an IRR of 12 per cent; but the real estate will bring a return upwards of 40 per cent.

Not only is the real estate return attractive, but there is a relatively quick return of capital invested; depending on the number of units available and the market area of the resort, a well-thoughtout scheme should sell out the real estate component over a period of five to seven years.

Very rarely will the developer be interested in developing and operating all the elements of a mixed-use resort: opportunities exist to sell on the development of individual parts or to take on board some or all of the development/operating risk. This becomes the first and most important decision to take in considering such a development, even before deciding where to develop. The developer should consider what risk it wants to take:

- the planning risk

- the development risk

- the operating risk. 
The more risk taken, the greater the return
Development state requires a long-term view to investment

\section{Planning risk}

This element of a project assumes that the developer has taken on a project which has yet to receive full planning for a development. It is possible to buy virgin land with no zoning, land with some tourist zones which are yet to be defined or land with specific tourist potential - with some limitations, these are normally the number of bed spaces that may be developed or the amount of buildable area allowed.

The more risk taken the greater the return, inevitably. It is possible to identify sites under single or multiple ownership that would be suitable for tourist development but have not yet received initial planning within a local structure plan. The developer has the opportunity to compile a site and then apply for tourist use and ultimately full planning - a long and risky road offering huge returns.

\section{Development risk}

A developer may wish to remove the planning risk by buying into a project that has either received zonal/tourist planning use, or indeed a site with specified levels of development opportunity granted by local or regional planning authorities. The level of planning granted will to a large extent govern the price paid.

The developer then has the opportunity to masterplan the site and apply for full planning - within the designated guidelines for the site. How much of this development risk it wants to take on forms part of the next decision process. The development of all of the components mentioned earlier on a single mixed-use site requires a great deal of skill, experience and investment. It is not unusual for such developments to have a total capital expenditure in excess of $€ 100 \mathrm{~m}$. There are investors who seek to buy hotels, golf courses, real estate development plots and retail opportunities on such sites that they can build and operate as an independent (yet closely linked) business from the rest of the resort.

\section{Operating risk}

Having taken the development through construction, each component requires specialist operating vehicles: hotel operators, real estate sales agents, retail management and so on. The developer may retain ownership of all components and buy in these skills, or sell the finished product to owners/operators/investors within each sector. This development stage requires a long-term view to investment; a hotel may not start making profit until year three or four of operation, and the typical payback will be in excess of seven years. A sales programme for several hundred units of real estate may be expected to extend over five to seven years.

\section{DEVELOPMENT OPPORTUNITIES}

This first decision (what do I want to do, what can I do, what level of investment and what risk can I take?) is all-important; going into 


\section{Create a place - not a project}

a project without a clear understanding of objectives, risk and timescale will create huge problems later on.

Having established the strategy it is possible to begin the process of deciding what to develop and where. As stated earlier, opportunities exist all over the world and each and every opportunity comes with its own very different risks and rewards. While mixed-use resorts may be developed anywhere, they do have certain physical criteria which must be evident:

- they must be accessible to source markets

- they must have a focal point, whether it be sea, golf, mountain views etc.

- they must have some identity: e.g. a golf resort, a marina, a skiing resort

- they must create the destination by adding a sport or activity or theme, or complement the destination, emphasising the attributes of a beach or mountain or desert location.

To use the catch phrase of a well-known architect and master planner, create a place - not a project!

A very simple approach may be to begin the process by deciding on a development in either a mature resort environment or an emerging resort environment. Developments in a mature market may take one to Spain, Portugal, Tuscany, Florida or Malta. Emerging markets are much more widespread, and include Bulgaria, Morocco, Libya, Black Sea destinations, Dubai, Finland, Slovenia .... and so on. Some of these locations hold more risk than others, but the risks to be considered are similar.

- What is the political risk?

- What is the economic risk?

- What is fashionable, or might be in the future?

- Is there stability in the local and adjoining market areas?

- Are source markets likely to be attracted to this destination?

- Is finance going to be available within this emerging market area?

- What component mix within the mixed-use resort would be most attractive?

It is at this stage that some professional consultancy advice should be sought, covering areas such as financial risk in the new market area, market demand and financial feasibility for the proposed development and identification of potential source markets with their strengths, needs and expectations.

This work should help define the concept plan for the resort, and if the consultants are working alongside the master planners a scheme can be compiled which is market driven, achievable and viable, without too much reworking as one moves through the planning process. 
What can one do and where?
Now the resort is ready for the real detail, in both planning terms and development terms, can planning parameters be stretched or changed? Does one build villas or sell plots? Which components does one keep, sell on, discard? But that is for another day, one is looking here at development opportunities: what can one do and where can one do it?

\section{Spain/Portugal}

These are very mature markets and a bit boring, but good, safe returns are still achievable. The Costa del Sol has seen real estate prices on mixed-use site developments rise by an average of 10 per cent per annum for the last five years. They will not make it this year, so has the bubble burst or is it just a cyclical slow-down? Perhaps now is the right time to start a new resort?

\section{Tuscany}

People are queueing up to buy real estate here, whether it is freehold, timeshare or fractional. There are not too many resorts around - mostly because it is extremely difficult to compile 100ha under single ownership! And even when this is achieved the owners want an unrealistic price. A tough market to play in, but the rewards and market need are there.

\section{Dubai}

Very fashionable, but little international investment is going into the country - it is all home grown. One needs a sponsor to do business in the country, and why would one want to sell real estate opportunities when the law does not even allow foreign ownership yet. Take a plot on 'dubailand' and do something really different high cost, bit of a risk, but what a challenge.

\section{North Africa}

Morocco is nearly a mature market, very high profile and expensive. There is room for middle-market destinations taking advantage of the profile given by the upmarket resorts. Politically and economically stable and a much better bet than its neighbours.

Libya is for the very brave: a very disorganised country with a lot of need and a lot of land, but tread carefully.

Egypt suffers every three to five years with some form of terrorist activity and it is hard to maintain profitable operations within the resorts. There are lots for sale, at prices less than replacement value, but does one want one?

Turkey, neither Africa nor Europe, has recently had its problems and is very well priced for those who choose this as a holiday destination. It sells on price and it is tough to make a profit; it lacks the archaeological attractions of Egypt and the stability of Morocco. 


\section{Eastern Europe}

City centres are the first to take off and many capital cities have sprouted major international hotels in recent years - Prague, Kiev and Warsaw to name a few, and even Sofia is on its way. This will quickly spread to resort environments outside the cities, and many development opportunities are evident in these countries. Real estate ownership is less of a problem within the EU countries, there is political and economic stability and one can build cheap, sell inexpensively and make a lot of money. The author has always been a little concerned, however, with the thought of going to Bulgaria for a golfing holiday when one could just as easily go to the Algarve and play one's favourite course.

\section{The Americas}

It would be tough going into the USA and taking them on in the resort development game, they do it so well - and it has to be said, better than Europeans. Their trick is almost exclusively to get funding right on day one, something Europeans always find difficult. They do not have a monopoly, though, and resort development in strong European market catchment areas such as Florida is feasible. The strong pound goes further in the development process and end users may well appreciate a European flavour.

Mexico is an exciting place to consider: lots of land, many new areas just opening up with infrastructure and access and again a strong pound provides an advantage. Many Spanish and Portuguese developers are looking, if not already active, in Mexico and South American countries, emulating their success in Cuba.

\section{CONCLUSION}

In conclusion, there are great opportunities, good returns and plenty of choice in what to develop, where and with whom. This paper will conclude with five sobering points on the downside of mixed-use developments.

\section{Five key points to consider}

- What to do when real estate is sold out?

- What if demand falls off or supply grows more than demand?

- Consider poor management structure - who owns what?

- What if airline access changes — budget airlines move out/in, airport subsidies, oil prices?

- What if legal ownership structures change (as in Portugal)? 